\title{
SMALL BOWEL PERMEABILITY IN DIAGNOSIS OF CELIAC DISEASE AND MONITORING OF COMPLIANCE OF A GLUTEN-FREE DIET (GUT PERMEABILITY IN CELIAC DISEASE)
}

\begin{abstract}
Pavel Kohout
University Teaching Hospital in Hradec Králové: Department of Gerontology and Metabolism

Summary: Background \& Aim : Celiac disease is an autoimmune disease with the damage of the intestinal barrier. The aim of study was to measure gut permeability in patients with untreated celiac disease and during treatment with a gluten free diet. Methods : 30 patients with celiac disease before and during treatment with gluten-free diet were investigated, 30 patients without organic damage of the gastrointestinal tract served as control. Small bowel permeability was measured using lactulose/mannitol and lactulose/D-xylose ratios. The saccharides were examined in the 5 hours collected urine using capillary gas chromatography. Results: Small bowel permeability (indices lactulose/mannitol and/or lactulose/xylose) increased significantly in patients with untreated celiac disease. 23 patients were followed up before and during treatment with a gluten-free diet 2-6 months after beginning of this treatment and small bowel permeability (measured as indices lactulose/mannitol and/or lactulose/xylose) significantly decreased. Conclusion : Small bowel permeability test is a non-invasive test suitable for the diagnosis of celiac disease and monitoring of compliance to a gluten-free diet in these patients.
\end{abstract}

Key words: Gut permeability; Lactulose; Mannitol; D-xylose; Celiac disease; Gluten-free diet

\author{
Abbreviations : \\ DTPA - Diethyl-triamino-propionic acid \\ EDTA - Ethylen-diamino-tetraacetic acid \\ LA/MA - Index lactulose/mannitol \\ LA/XY - Index lactulose/D-xylose \\ NSAID - Non-steroidal anti-inflammatory drug \\ SD - Standard deviation
}

\section{Introduction}

Celiac disease is an autoimmune disease with presence of antibodies against gliadine causing damage to enterocytes and villous atrophy in sensitive patients (1). Celiac disease is a suitable model of gut barrier damage with an increase of small bowel permeability (2). There are two theories explaining the increase of small bowel permeability in villous atrophy (2). One theory differentiates the various ways of absorption of saccharides according to molecular size: the monosaccharides (e.g. mannitol, L-rhamnose) are absorbed passively via enterocytes (passive transcellular absorption); other monosaccharides (D-xylose) are absorbed by facilitated diffusion (active transport after concentration); glucose, amino acids and dipeptides are absorbed by active, carrier mediated transport, which is $\mathrm{Na}^{+}-\mathrm{K}^{+}$-ATPase dependent. Disaccharides are absorbed paracellularly via tight junctions. If the small mucose is damaged, transcellular absorption decreases and paracellular absorption increases due to adaptation to worsening absorption.
According to the second theory both monosaccharides and disaccharides are absorbed paracellularly via tight junctions, monosaccharides on villous tips and disaccharides in crypts. In case of villous atrophy all saccharides are absorbed in crypts and absorption of disaccharides is relatively higher $(2,9,12)$.

Patients with untreated celiac disease show villous atrophy of small bowel mucosa; small bowel permeability is increased and after treatment by a gluten-free diet the mucosal architecture is reconstructed and small bowel permeability decreases to normal values $(3,6,14,15,16)$.

\section{Patients}

30 patients ( 7 males, 23 females) aged $39+-13$ years with celiac disease were included in the study; 30 patients ( 8 males, 22 females) aged $38+-12$ years with non-specific gastrointestinal problems served as controls (Table 1).

Diagnosis of celiac disease was made using histological and serological examinations (anti-gliadine, anti-endomysium 
Tab. 1: Characteristics of patients and control group.

\begin{tabular}{|l|c|c|c|c|c|c|c|}
\hline & No. & Male & Female & $\begin{array}{c}\text { Age } \\
\text { Mean }\end{array}$ & SD & Min. & Max. \\
\hline $\begin{array}{l}\text { Celiac } \\
\text { Disease }\end{array}$ & 30 & 7 & 23 & 38.7 & 13.2 & 20 & 69 \\
\hline Controls & 30 & 8 & 22 & 38.2 & 12.3 & 18 & 62 \\
\hline
\end{tabular}

SD - standard deviation

and anti-reticuline antibodies) and improvement by a glutenfree diet.

Patients of the gastroenterological outpatient department with non-specific gastrointestinal problems after exclusion of celiac disease and/or inflammatory bowel diseases served as controls.

23 patients with celiac disease (6 males, 17 females) aged 38.5 years were followed for 2-6 months after a glutenfree diet; small bowel permeability was assessed before and during the treatment with a gluten-free diet.

\section{Methods}

Small bowel permeability was measured using lactulose/mannitol and lactulose/xylose ratios. Test solution contents were $10.0 \mathrm{~g}$ lactulose, $2.0 \mathrm{~g}$ mannitol, $2.0 \mathrm{~g}$ D-xylose and $11.0 \mathrm{~g}$ glucose in $100 \mathrm{ml}$ distilled water; osmolarity of this test solution was 1500 mosmol/l. The high osmolarity of this solution is used to increase the sensitivity of the small bowel permeability test.

The test solution was drunk by patients after overnight fasting. Urine was collected 5 hours later and stabilized using thiomersal; the concentrations of sugars were measured using capillary gas chromatography after their conversion to oximes and silylation, Hewlett Packard 5890 II chromatograph and Hewlett Packard 3396A integrator were used. The amounts of excreted sugars (lactulose, mannitol, D-xylose) were expressed as the ratio of orally given substances in percents. This procedure does not require desalting and is described in previous literature (4).

The index of small bowel permeability was calculated as the lactulose/mannitol (LA/MA) and lactulose/D-xylose (LA/XY) ratios, respectively.

The examination of small bowel permeability was performed in patients with untreated celiac disease and in the control group. In the second part of our study, small bowel permeability was measured in patients with celiac disease before and after treatment with a gluten-free diet (2-6 months).

The parametric tests (non-paired and paired $\mathrm{T}$ tests) were used in the statistical analysis of results.

\section{Results}

Small bowel permeability was measured in patients with untreated celiac disease and compared with controls.
Absorption of lactulose in both groups was 1.518 vs. 0.258 respectively, absorption of mannitol was 8.003 vs. 15.551 and absorption of D-xylose was 14.663 vs. 20.56, respectively. The values of absorption of all saccharides were significantly statistically different (Table 2). Small bowel permeability index - lactulose/mannitol (LA/MA) - was significantly higher in patients with untreated celiac disease than in the control group ( 0.303 vs. 0.016$)$; a similar difference was in both examined groups using the lactulose /D-xylose index (LA/XY), 0.104 vs. 0.013 (Table 2.). The maximum value of LA/MA index was 72 times higher in patients with untreated celiac disease than in the control group, 2.33 vs.0.032 (Table 3 ). LA/XY index is significantly higher in patients with untreated celiac disease (Table 4).

Tab. 2: Absorption of saccharides in patients with celiac disease.

\begin{tabular}{|l|c|c|c|c|c|}
\hline & Lactulose & Mannitol & D-xylose & LA/MA & LA/XY \\
\hline $\begin{array}{l}\text { Celiac } \\
\text { Disease }\end{array}$ & 1.518 & 8.003 & 14.663 & 0.303 & 0.104 \\
\hline $\begin{array}{l}\text { Control } \\
\text { Pat. }\end{array}$ & 0.259 & 15.551 & 20.56 & 0.016 & 0.013 \\
\hline $\begin{array}{l}\text { Stat. } \\
\text { Signific. }\end{array}$ & $* * *$ & $* * *$ & $*$ & $* * *$ & $* * *$ \\
\hline
\end{tabular}

$* \mathrm{p}<0.05 \quad * * * \mathrm{p}<0.001$

LA/MA - Index Lactulose/Mannitol

LA/XY - Index Lactulose/D-xylose

Tab. 3: Small bowel permeability in patients with celiac disease (LA/MA).

\begin{tabular}{|l|c|c|c|c|c|}
\hline & No. & $\begin{array}{c}\text { LA/MA } \\
\text { Mean }\end{array}$ & SD & Min. & Max. \\
\hline Celiac Disease & 30 & 0.303 & 0.451 & 0.02 & 2.33 \\
\hline Control Patients & 30 & $\begin{array}{c}0.016 \\
* * *\end{array}$ & 0.008 & 0.001 & 0.032 \\
\hline
\end{tabular}

$* * * \mathrm{p}<0.001$

LA/MA - Index Lactulose/Mannitol

SD - Standard deviation

Tab. 4: Small bowel permeability in patients with celiac disease $(\mathrm{LA} / \mathrm{XY})$.

\begin{tabular}{|l|c|c|c|c|c|}
\hline & No. & $\begin{array}{c}\text { LA/XY } \\
\text { Mean }\end{array}$ & SD & Min. & Max. \\
\hline Celiac Disease & 30 & 0.104 & 0.237 & 0.0394 & 1.167 \\
\hline Control Patients & 30 & $\begin{array}{c}0.013 \\
* * *\end{array}$ & 0.009 & 0.0006 & 0.017 \\
\hline
\end{tabular}

$* * * p<0.001$

LA/XY - Index Lactulose/D-xylose

SD - Standard deviation 
23 patients with celiac disease were examined after treatment with a gluten-free diet; the absorption of lactulose decreased from 1.58 to $0.46 \%$; the absorption of mannitol and D-xylose increased from 7.89 to 12.3 and from 14.46 to 20.20 respectively (Table 5 .).

The LA/MA index decreased statistically significantly, from 0.346 to 0.043 , and the LA/XY index decreased also from 0.192 to.0,025 (Table 5).

LA/MA and LA/XY indices are suitable for monitoring a gluten-free diet in patients with celiac disease.

Tab. 5: Small bowel permeability after treatment by a gluten-free diet.

\begin{tabular}{|l|c|c|c|c|c|c|}
\hline & No. & LA & MA & XY & LA/MA & LA/XY \\
\hline $\begin{array}{l}\text { Untreated } \\
\text { Celiac } \\
\text { Sprue }\end{array}$ & 23 & 1.58 & 7.89 & 14.46 & 0.346 & 0.192 \\
\hline $\begin{array}{l}\text { Gluten - } \\
\text { Free Diet }\end{array}$ & 23 & $\begin{array}{c}0.46 \\
* * *\end{array}$ & $\begin{array}{c}12.30 \\
* *\end{array}$ & $\begin{array}{c}20.20 \\
*\end{array}$ & $\begin{array}{c}0.043 \\
* * *\end{array}$ & $\begin{array}{c}0.025 \\
* * *\end{array}$ \\
\hline
\end{tabular}

$* \mathrm{p}<0.05 * * \mathrm{p}<0.01 * * * \mathrm{p}<0.001$

LA - Lactulose

MA - Mannitol

XY - D-xylose

LA/MA - Index Lactulose/Mannitol

LA/XY - Index Lactulose/D-xylose

\section{Discussion}

Small bowel permeability tests are used for elucidation of gut barrier damage in various diseases (2). Small bowel permeability is increased in patients with celiac disease (3), non-steroidal antiiflammatory drug (NSAIDs) enteropathy (2), cytostatic drug-induced enteropathy (10), in critically ill patients with sepsis, burns and/or polytrauma $(2,9)$ and during relapses of inflammatory bowel diseases (both Crohn's disease and ulcerative colitis) (12).

Tests with various saccharides (lactulose/mannitol, lactulose/rhamnose, cellobiose/rhamnose), chelates $\left({ }^{51} \mathrm{Cr}\right.$ EDTA, ${ }^{99 m}$ Tc-DTPA) or polyethylenglycoles with various molecular sizes are used for examination of small bowel permeability. In our study the following saccharides were used : lactulose, mannitol and D-xylose $(8,9)$.

The saccharides in urine are measured using enzymatic methods, high frequency liquid chromatography (HPLC) or capillary gas chromatography. Capillary gas chromatography does not require desalting and is suitable for the assessment of saccharides in urine (4).

Menzies described the increase of intestinal permeability in patients with villous atrophy in 1974, tests with two saccharides with various molecular sizes were used (13). Juby in 1989 assessed 1010 patients from a gastroenterologic outpatient department; a test with cellobiose and rhamnose had for untreated celiac disease $96 \%$ sensitivity,
$70 \%$ specificity and negative predictive value was $99 \%$ (7). The same results were found with lactulose and mannitol (8). The increased value of small bowel permeability is described by different authors in patients with celiac disease and dermatitis herpetiformis Duhring (3). The increase of permeability was described in children and adult patients with untreated celiac disease (11). In our study small bowel permeability is significantly higher in patients with untreated celiac disease than in control patients (patients with functional disorders without organic damage of the gastrointestinal tract). Lactulose/mannitol and lactulose/D-xylose indices are statistically significantly higher on $p<0.001$; statistical significance of difference of D-xylose absorption is $\mathrm{p}<0.05$.

In patients treated by a gluten-free diet small bowel permeability decreases to normal values $(5,15,16,17)$. In our study lactulose/mannitol and lactulose/D-xylose indices decrease statistically significantly $(p<0.001)$ in patients with celiac disease after treatment by a gluten-free diet for 2-6 months.

The results of our study in agreement with the other papers show that small bowel permeability test with lactulose, mannitol and D-xylose is suitable for diagnosis of celiac disease and monitoring of compliance to a gluten-free diet.

Research was supported by the Internal Grant Agency Ministry of Health Czech Republic Nr. 4529-3 and PRO-MED.CS Prague a.s.

\section{References}

1. Bai JC. Malabsorption syndromes. Digestion 1998;59:530-46.

2. Bjarnason I, MacPherson A, Holander D. Intestinal permeability : An overview. Gastroenterology 1995;108:1556-81.

3. Bjarnason I, Marsh MN, Price A, Levi AJ, Peters TJ. Intestinal permeability in patients with coeliac disease and dermatitis herpetiformis. Gut 1985;26:1241-9.

4. Brátová $\mathrm{M}$, Kohout $\mathrm{P}$. The measurement of lactulose, mannitol and D-xylose using capillary gas chromatography. Clin Biochem Metabol 1998;27:98-101.

5. Cummings AG, Pentilla IA, Labrooy JT, Robb TA, Davidson GA. Recovery of the small intestine on coeliac disease on a gluten-free diet : changes in intestinal permeability, small bowel morphology and T-cell activity. J Gastroenterol Hepatol 1991;6:53-7.

6. van Elburg RM, Uil JJ, Mulder CJJ, Heymans HSA. Intestinal permeability in patients with coeliac disease and relatives of patients with coeliac disease. Gut 1993;34:354-7.

7. Juby LD, Rothwell J, Axon ATR. Cellobiose/mannitol sugar test - a sensitive tubeless test for celiac disease : results on 1010 unselected patients. Gut 1989;30:476-80.

8. Juby LD, Rothwell J, Axon ATR. Lactulose/mannitol test : An ideal screen for celiac disease. Gastroenterology 1989;96:79-85.

9. Kohout P. The examination of small bowel permeability. Czech Slov Gastroenterol 1998;52(Suppl):15-27.

10. Kohout P, Cerman J, Brátová M, Zadák Z. Small bowel permeability in patients with cytostatic therapy. Nutrition 1999;15:546-9.

11. Kuitunen M, Savilahti E. Gut permeability to human \&-Lactalbumin, bLactoglobulin, Mannitol, and Lactulose in Celiac Disease. J Ped Gastroenterol Nutr 1996;22:197-204.

12. Meddings JB. Review article : Intestinal permeability in Crohn's disease. Aliment Pharmacol Ther 1997;11(Suppl 3):47-56.

13. Menzies IS. Absorption of intact oligosaccharides in health and disease. Biochem Soc Trans 1974;2:1040-6.

14. Troncone R, Caputo N, Micillo M, Maiuri L, Poggi V. Immunologic and intestinal permeability tests as predictors relapse during gluten challenge in childhood coeliac disease. Scand J Gastroenterol 1994;39:144-7.

15. Uil JJ, van Elburg RM, Mulder CJJ, Heymans HSA. The value of D-xylose test compared with differential sugar tests in recognizing coeliac disease. Neth J Med 1996;49:68-72. 
16. Uil JJ, van Elburg RM, van Overbeek FM, Meijer JWR, Mulder CJJ, Heymans HSA. Follow-up of treated coeliac patients : sugar absorption test and intestinal biopsies compared. Eur J Gastroenterol Hepatol 1996;8:219-23.

17. Ukabam SO, Cooper BT. Small intestinal permeability as an indicator of jejunal mucosal recovery in patients with celiac sprue on gluten-free diet. J Clin Gastroenterol 1985;7:232-6.

Research was supported by the Internal Grant Agency Ministry of Health Czech Republic Nr. 4529-3 and PRO-MED.CS Prague a.s.

Submitted June 2001.

Accepted November 2001.

MUDr. Pavel Kohout, Ph.D.,

University Teaching Hospital in Hradec Králové, $I^{\text {nd }}$ Department of Internal Medicine,

Sokolská 581,

50005 Hradec Králové,

Czech Republic.

e-mail: kohout@lfhk.cuni.cz 